\title{
Grundtvig-litteratur 1997-2000. En bibliografi
}

\author{
Ved Aage Jørgensen
}

Nedenstående bibliografi over Grundtvig-litteratur 1997-2000 viderefører tilsvarende bibliografier i Grundtvig Studier 1968, 1971, 1974, 1979, 1984, 1991 og 1997 (kumuleret udgave - dækkende årene 19631985 - offentliggjort 1986).

Stoffet er ordnet efter bibliografiske kriterier frem for efter emnekredse. Tidsrummet gælder ikke absolut, idet enkelte bidrag af ældre og nyere dato er medtaget. Arbejdet er afsluttet 1.6.2001.

Med hensyn til avisstoffet (artikler fortegnet ndf. i afsnit 6, samt anmeldelser fortegnet $\mathrm{i}$ forbindelse med de arbejder, de omhandler) gælder, at bibliografien ikke gør krav på fuldstændighed. Medtaget er i alt væsentligt, hvad også Artikelbasen (den elektroniske videreførelse af Dansk artikelindeks og Dansk anmeldelsesindeks) har fundet det rimeligt at redde fra glemsel.

\section{Bibliographica}

Jørgensen, Aage, „Grundtvig-litteratur 1991-1996. En bibliografi«. Grundtvig Studier, 1997, s. 228-58.

\section{Udgaver}

Selected Educational Writings. Udg. af Max Lawson. 1991. $110 \mathrm{~s}$. (Indledning, »Profile: N. F. S. Grundtvig, 1783-1872«, s. 7-18.)

'Så skall orden evigt glöda'. Dikter och psalmer i urval och översättning av Inge Löfström. Stockholm, 1998. 135 s. (Heri: „Grundtvig kom aldrig till Sverige. Mänskligt och gudomligt i harmoni - i Danmark «, s. 118-28 [forf.'s 'Det eviga i en bägare vatten'. Studier och reflexioner, Stockholm 1992, s. 67-82; forkortet].) (Anm.: Søren Sørensen, Hymnologiske Meddelelser, XXIX, 2000, s. 193-97.) 


\section{Bøger}

Abrahamowitz, Finn, Grundtvig. Danmarktil lykke. 2000. 413 s. (Anm.: Søren Krarup, Tidehverv, LXXIV, 2000, s. 231-32.) (Anm.: Claus Bjørn, Kristeligt Dagblad 8.9.2000; Johs. H. Christensen, JyllandsPosten 8.9.2000; Sørine Gotfredsen, Aktuelt 9.9.2000; Steffen Heiberg, Politiken 9.9.2000; Niels Højlund, Højskolebladet, 2000, nr. 27, s. 9-11; Finn Jacobi, Dansk Kirketidende, CLII, 2000, s. 304-06; Jens Kistrup, Weekendavisen/Bøger 8.9.2000; Kathrine Lilleør, Berlingske Tidende 8.9.2000; Sture Näslund, Nordisk tidskrift för vetenskap, konst och industri, LXXVII, 2001, s. 100-02; Klaus Rifbjerg, Information 15.9.2000.) (Cf. interviews med FA: Orla Borg, Jyllands-Posten 22.10.2000; Helene Moe, Kristeligt Dagblad 7.9.2000.)

Allchin, A. M., N. F. S. Grundtvig. An Introduction to his Life and Work. 1997. 336 s. (Skrifter udg. af Grundtvig-Selskabet, 27.) (Også fremkommet i London.) (Anm.: Sune Auken, Information 10.9.1997; Torben Bramming, Prcesteforeningens Blad, LXXXVIII, 1998, s. 13941; Hans Raun Iversen, Dansk teologisk Tidsskrift, LXI, 1998, s. 15762; David R. Law, Journal of Theological Studies, L, 1999, s. 398-403; Viggo Mortensen, Grundtvig Studier, 1998, s. 268-72; George Pattison, Modern Believing, 39:2, 1998, s. 53-55; Henrik Wigh-Poulsen, Fønix, XXII, 1998, s. 187-89.)

Allchin, A. M., S. A. J. Bradley, N. A. Hjelm \& J. H. Schjørring (red.), Grundtvig in International Perspective. Studies in the Creativity of Interaction. 2000. x, 209 s. (Indhold: A. M. Allchin, "Introduction«, s. 5-25; Philip Hefner, »Theology and Creation. Joseph Sittler and N. F. S. Grundtvig«, s. 27-44; Michael Root, "Generous Orthodoxy. Regin Prenter's Appropriation of Grundtvig«, s. 45-58; Axel C. Kildegaard, "Danish Grundtvigians in the United States. Challenges Past and Present«, s. 59-73; R. William Franklin, »Grundtvig Within the Ecclesiological Revival of 19th-Century Europe«, s. 75-85; Vítor Westhelle, "'The Noble Tribe of Truth'. Etchings on Myth, Language, and Truth Speaking «, s. 87-102; Jakob Balling, »Old Europe and its Aftermath. Poetry, Doctrine, and Western Culture «, s. 103-14; Christian Thodberg, "Grundtvig's View of the Bible«, s. 115-33; A. M. Allchin, "The Holy Spirit in the Teaching of N. F. S. Grundtvig«, s. 135-46; S. A. J. Bradley, "'A Truly Proud Ruin'. Grundtvig and the Anglo-Saxon 
Legacy«, s. 147-62; Gustav Björkstrand, „Grundtvig's 'Education for Life' and the Cultural Challenge Facing the Baltic and Nordic Countries Today «, s. 163-72; Asoke Bhattacharya, »Adult Education in India. Relevance of Grundtvig", s. 173-84; K. E. Bugge, "Some International Varieties of Grundtvig Inspiration«, s. 185-92; Holger Bernt Hansen, "Education for Life or for Livelihood? Grundtvig and the Third World Revisited«, s. 193-206.) (Anm.: Jakob Holm, Kristeligt Dagblad 24.8.2000; Erik Kelstrup, Dansk Kirketidende, 2000, s. 287-90; Mikkel Wold, Information 1.9.2000.)

Andersen, Kirsten M. (red.), Et kor af stemmer. Tematiske laesninger $i$ salmebogen. 1997. 266 s. (Indhold: Forord s. 7-12; Jørgen Kjærgaard, »Paradis af ørke! Paradisforestillinger og paradisforkyndelse i salmebogen «, s. 13-48; Jakob Balling, »Udgang, overgang, pilgrimsgang «, s. 49-58; Lisbeth Smedegaard Andersen, »Den blinde skæbne og Guds forsyns øje«, s. 59-85; Karin Friis Plum, »'Vi kysse dig med Suk og Bøn’. Salmens erotiske metaforik «, s. 87-117; Christian Thodberg, »Den dårlige samvittighed eller lovsangens klangbund. Hjertet hos Brorson og hos Grundtvig «, s. 119-44; Troels Nørager, ॥"Ak, kom, jeg vil oplukke ...'. Den religiøse inderlighed hos Brorson «, s. 145-75; Carsten BachNielsen, "Lys i mørke, liv i død. Om nat og dag i salmebogen«, s. 177216; Henrik Wigh-Poulsen, »Landskaber«, s. 217-48; Erik Skyum-Nielsen, "Når skaberværket skrumper ind. Om salmebogens rum-dimension«, s. 249-66.) (Anm.: Hans Boas, Grundtvig Studier, 1998, s. 28388; Henriette Bacher Lind, Proesteforeningens Blad, LXXXVIII, 1998, s. 507-10.)

Behrendtz, Lennart \& Björn Skogar (red.), Grundtvig, Geijer och deras verkningshistoria. Rapport från ett symposium på Högskolan $i$ Karlstad, 1996. Karlstad, 1997. 131 s. (Heri bl.a.: Kim A. Pedersen, "Grundtvig og Geijer - to møder og en afsked. En redegørelse for forbindelserne mellem Erik Gustav Geijer og N. F. S. Grundtvig, indeholdende en transskription af Fascikel $379.24 \mathrm{og}$ Fascikel 379.80 med Grundtvigs to udkast til en tale til Geijer i 1846«, s. 31-42; id., »Grundtvigs syn på kristendom og folkeliv«, s. 43-64; Jens H. Schjørring, »Kirken i historien. Et grundmotiv i N. F. S. Grundtvigs kirkesyn som oplæg til en sammenligning med E. G. Geijer«, s. 65-81; K. E. Bugge, »Den grundtvigske fortæller - før og nu«, s. 83-103; Harry Aronson, »Identitetsskapande 
idéer i Danmark och Sverige: folklighet och personlighet«, s. 105-31.) (Anm. af bogen: Gert Nilsson, Grundtvig Studier, 1998, s. 280-83.)

Bergstedt, Bosse, Den livsupplysande texten. En läsning av N.F.S. Grundtvigs pedagogiska skrifter. Stockholm, 1998. 362 s. (Akad. avh., forsvaret på Linköpings universitet 30.1.1998; engelsk resumé s. 280-90; opposition af K. E. Bugge, Grundtvig Studier, 1998, s. 81-94.) (Anm.: Ole Vind, Højskolebladet, 1998, nr. 38, s. 11-12.)

Bradley, S. A. J., Transcriptions of the Exeter Book. Grundtvig Archive Fascicle 316, nrs 1-8 in the Royal Library Copenhagen. An Analysis. 1998. $77 \mathrm{~s}$. (Skrifter udg. af Grundtvig-Selskabet, 28.)

Bugge, K. E., Canada og Grundtvig. 1997. 168 s.

Bugge, K. E., Canada and Grundtvig. Overs. af David Stoner. 1999. $156 \mathrm{~s}$.

Bugge, K. E., Spor i sne. 1999. 275 s. (Heri bl.a.: »Grundtvigs syn på folkelig dannelse - dets muligheder før og nu«, s. 23-40 [1993]; »Den grundtvigske fortæller «, s. 41-66 [1997]; »Lokal forankring og universelt perspektiv i Grundtvigs salmedigtning «, s. 67-81 [1995]; »Englene i Grundtvigs skolesangværk « [afskedsforelæsning 30.10.1998], s. 25972.)

Buhl, Peter Neerup, Grundtvig og nutidens kamp for Danmark. 2000.87 s. (Anm.: Kræn Christensen, Dansk Kirketidende, CLIII, 2001, s. 14-16 [replik hertil: Johannes Jørgensen, s. 38-39]; Erling Glad, Kristeligt Dagblad 25.11.2000; Sørine Gotfredsen, Aktuelt 9.9.2000.) (Cf. hertil: Søren Krarup, »Om Grundtvig«, Tidehverv, LXXIV, 2000, s. 171-73.)

Christensen, Bent, Omkring Grundtvigs Vidskab. En undersøgelse af N. F.S. Grundtvigs forhold til den erkendelsesmoessige side af det kristeligt nødvendige livsengagement. 1998. $630 \mathrm{~s}$. (Skrifter udg. af GrundtvigSelskabet, 31.) (Engelsk resumé s. 538-53.) (Disputats, forsvaret på Københavns Universitet 4.9.1998; oppositionsindlæg: Anders Pontoppidan-Thyssen, Grundtvig Studier, 1999, s. 94-110, og Theodor Jørgensen, smst., s. 111-20.) (Anm.: Rudolph Arendt, Kristeligt Dagblad 10.6.1998; Sune Auken, Information 31.8.1998; Svend Bjerg, Politiken 
31.8.1998; Karen Marie Mortensen, Fønix, XXII, 1998, s. 245-47; Ole Opstrup, Dansk Kirketidende, CLI, 1999, s. 11-13; Kim Arne Pedersen, Højskolebladet, 1998, nr. 27, s. 11-14; Poul Bo Sørensen, Proesteforeningens Blad, LXXXVIII, 1998, s. 1221-24.) (Cf. forf., "Livspoetisk indledning. Poesien på statholder-marken. En slags indfrielse af en bebudelse og i hvert fald et bidrag til samtalen om 'at være grundtvigsk i dag' ", Dansk Kirketidende, CLII, 2000, s. 202-06 og 218-26.)

Fernando, W. J. Basil, Demoralization and Hope. A Comparative Study of the Ideas of N. F. S. Grundtvig (1783-1872), Denmark, and B. R. Ambedkar (1881-1956), India. Hong Kong, 2000. vi, 133 s. (Udg. af Asian Human Rights Commission.)

Golf, Olav, Norgesvennen Grundtvig. 'Giv mig Gud, en Salmetunge'. Oslo, $2001.197 \mathrm{~s}$.

Grell, Helge, Vision og virkeliggørelse. En redegørelse for Grundtvigs tanker om folkelig oplysning og en folkelig højskole og for forsøget på at virkeliggøre dem. 1998. $154 \mathrm{~s}$. (Skrifter udg. af Grundtvig-Selskabet, 29.) (Anm.: Sune Auken, Information 27.3.1998; Torben Bramming, Proesteforeningens Blad, LXXXVIII, 1998, s. 625-27; Søren Jensen, Grundtvig Studier, 1998, s. 277-79.)

Hansen, Benny Kastrup, Grundtvigs vision. Folkelig dannelse, folkelig oplysning og ikke mindst folkehøjskolen. 1998. $52 \mathrm{~s}$. (Plastbrevmappe udg. af Seminariet for Formgivning, Nykøbing F.)

Haslam, Gerald M., N. F. S. Grundtvig's 'Fcedrenearv' (1783-1815). 1998. $425 \mathrm{~s}$. (Skrifter udg. af Grundtvig-Selskabet, 30.) (Heri appendices 1-3 [hidtil utrykte breve m.v.] s. 216-393.)

Holm, Anders, Historie og efterklang. En studie i N. F. S. Grundtvigs tidsskrift 'Danne-Virke'. 2001. 139 s. (Anm.: Niels Højlund, Højskolebladet, 2001, nr. 8, s. 8-9.)

Jensen, Gunnar, De levendes land. Drøm og virkelighed. En fortolkning af Grundtvigs digt i tekst og billeder. 1997. 145 s. (Anm.: Wagner Jensen, Dansk Kirketidende, CL, 1998, s. 62-63; Claus Grymer, "Borger i de levendes land «, Kristeligt Dagblad 8.4.1997 [interview med GJ].) 
Korsgaard, Ove (red.), En orm - en gud. Om mennesket i verden. 1997. 212 s. (Indhold: Ove Korsgaard, "Om Grundtvigs kosmologi og psykologi«, s. 13-40; Niels Buur Hansen, »Mennesket i verden, verden i mennesket «, s. 41-61; Hans Hauge, »Om mennesket om natten «, s. 6376; Bosse Bergstedt, "En vandring i menneskets billede«, s. 77-104; Uffe Jonas, "Tiden før Selvet - Grundtvig og det historiske menneske«, s. 105-52; Knud Bjarne Gjesing [udg.], »N. F. S. Grundtvig: Om Mennesket i Verden «, s. 153-205.) (Anm.: Doris Ottesen, Kristeligt Dagblad 15.8.1997; Ole Vind, Højskolebladet, 1997, nr. 28, s. 10-13; Mikkel Wold, Information 10.9.1997.) (Til Ove Korsgaards bidrag: Per Warming, "With Grundtvig on our Side - om Grundtvigs kosmologi«, Højskolebladet, 1998, nr. 3, s. 5-7.)

Kvist, Vagn, 'Guds cerinde går hver en storm'. 1997. 115 s. (33 salmelæsninger, heraf 21 af G-salmer; oprindelig trykt i dagbladet Vestkysten, 1983-90.) (2. udg., 1998.)

Meincke, Inga, Vox Viva. Die 'wahre Aufklärung' des Dänen Nikolaj Frederik Severin Grundtvig. Heidelberg, 2000.371 s. (Skandinavistische Arbeiten, 17.) (Diss., Frankfurt a.M., 1998.)

Reich, Ebbe Kløvedal, Solskin og lyn. Grundtvig og hans sang til livet. 2000. 248 s. (Bilagt dobbelt-CD af Niels-Henning Ørsted Pedersen, Ole Kock Hansen, m.fl.) (Anm.: Carsten Bach-Nielsen, Kristeligt Dagblad 26.9.2000; Bjørn Bredal, Politiken 26.9.2000; Johs. H. Christensen, Jyllands-Posten 26.9.2000 [ufærdig version]; Ulrik Høy, Weekendavisen/Bøger 29.9.2000; Erik Møller, Proesteforeningens Blad, XC, 2000, s. 1193-95; Kathrine Lilleør, Berlingske Tidende 26.9.2000; Sture Näslund, Nordisk tidskrift för vetenskap, konst och industri, LXXVII, 2001, s. 100-02; Klaus Rifbjerg, Information 19.10.2000; Niels Thomsen \& Jytte Lundbak, Dansk Kirketidende, 2000, s. 300-04; Niels Højlund, Højskolebladet, 2000, nr. 29, s. 12-13.) (Cf. Henrik WighPoulsen, "Grundtvig vender tilbage. Nogle hektiske Grundtvig-dage i september«, Dansk Kirketidende, CLII, 2000, s. 296-300.)

Sacalis, Nicolae, N. F. S. Grundtvig danaismul si civilizatia nordica. Bucuresti, [1999]. $267 \mathrm{~s}$. 
Sørensen, Preben (red.), O, dejlige land. 1998. 160 s. (Heri bl.a.: Kim Arne Pedersen, »Hvad betyder det grundtvigske i dag?«, s. 54-68 [cf. ndf. u. »Tidsskriftartikler «]; Frederik Christensen, »Den grundtvigske familie«, s. 70-81; Niels Henrik Arendt, " Når du ej dit ord vil sende, er din kirke ikke til'. Om gudstjenesten i Den danske Folkekirke«, s. 10417.) (=Vartovbogen, 1998.)

Vind, Ole, Grundtvigs historiefilosofi. 1999. 645 s.(Engelsk resumé s. 615-20.) (Disputats, forsvaret på Københavns Universitet 28.5.1999; oppositionsindlæg: Gunhild Nissen, Historisk Tidsskrift, IC, 1999, s. 510-26.) (Anm.: Svend Bjerg, Politiken 27.5.1999; Niels Højlund, Højskolebladet, 1999, nr. 16, s. 8-10; Christian de Fine Licht, Kristeligt Dagblad 27.5.1999; Karen Marie Mortensen, Prcesteforeningens Blad, LXXXIX, 1999, s. 992-95; Jes Fabricius Møller, 1066, XXIX:3, 1999, s. 36-38; Kathrine Lilleør Petri, Berlingske Tidende 24.7.1999; Jens Rahbek Rasmussen, Weekendavisen/Bøger 16.7.1999; Henrik WighPoulsen, Dansk Kirketidende, CLI, 1999, s. 206-08; Vagn Wåhlin, Historie, 2000, s. 183-86.) (Interview med OV: Palle Weis, Kristeligt Dagblad 28.5.1999.)

Vogel, Norbert, Grundtvigs Bedeutung für die deutsche Erwachsenenbildung. Ein Beitrag zur Bildungsgeschichte. Bad Heilbrunn, 1994. viii, 336 s. (Habilitationsschrift, Tübingen 1993.) (Anm.: Jens Holger Schjørring, Grundtvig Studier, 1997, s. 262-64; Johannes Værge, Weekendavisen 15.7.1994.)

Warren, Clay, Grundtvig's Philosophy of Lifelong Education through the Living World. Sydney, N.S. (Canada), 1987. iv, 27 s. (Tompkins Institute for Human Values and Technology. Occasional Papers, 3.)

Zøllner, Lilian (red.), Rodfcestet universalisme. N. F. S. Grundtvigs poesi, menneskesyn, kultursyn, skolesyn. 1996. 179 s. (Indhold: AnneMarie Steen Petersen, "Åndemasken på Bispebjerget «, s. 7-37 [om Grundtvigs Kirke]; Arthur Macdonald Allchin, »Personlig og national rodfæstethed og identitet i N. F. S. Grundtvigs værker«, s. 38-58; Håkan Eilert, "Grundtvig och Konfucius - att sammanbinda allt till enhet «, s. 59-80; Bernd Henningsen, «Demokratiet i et Europa i forandring. Den grundtvigske folkelighed og det civile samfund«, s. 81-98; Dmitri Gavra, »Et folk! Hvad er et folk? Grundtvigs indflydelse i et Europa under 
forvandling «, s. 99-124; Lilian Zøllner, "Når få har for meget og færre for lidt«, s. 125-51; Hajime Yano, »N. F. S. Grundtvigs tanker og Japan «, s. 152-63; Edicio dela Torre, »Er lyset for de lærde blot? De universelle aspekter i Grundtvigs skoletanker «, s. 164-78.) (Anm.: Bosse Bergstedt, Grundtvig Studier, 1998, s. 289-91; Kathrine Lilleør Petri, Berlingske Tidende 11.2.1997.)

\section{Dele af bøger}

Auken, Sune, Eftermale. En studie $i$ den danske dødedigtning fra Anders Arrebo til Søren Ulrik Thomsen. 1998. S. 31-35, 129-53, 220-23. Cf. reg. (Anm.: Kathrine Lilleør Petri, Prcesteforeningens Blad, LXXXIX, 1999, s. 543-45.)

Auken, Sune, »Naturen som tegn. Om Grundtvig og naturvidenskaben«. I: Mogens Bencard (red.), Krydsfelt. And og natur i Guldalderen. 2000. S. 214-23. (Engelsk udg., Intersections. Art and Science in the Golden Age, 2000.)

Bach-Nielsen, Carsten \& Jan Lindhardt (red.), Kirke og kristendom. Leksikon. 2001. S. 132. (Svend Bjerg om G.)

Bjerre, Karen \& Lisbeth Kiil (red.), Sanghåndbogen. 1999. 303 s. (Om 250 sange og salmer i Højskolesangbogen, 17. udg.) Se reg.

Bjork, Robert E., "Nineteenth-Century Scandinavia and the Birth of Anglo-Saxon Studies«. I: Allen J. Frantzen \& John D. Niles (red.), Anglo-Saxonism and the Construction of Social Identity. Gainesville, Fl., 1997. S. 111-32. Se reg. s. 235.

Bjørn, Claus, Dengang Danmark blev moderne - eller historien om den virkelige danske utopi. 1998. $120 \mathrm{~s}$. (Afsnittet $» I$ Grundtvigs fædreland ...» også i: Højskolebladet, 1998, nr. 33, s. 3-6.)

Borish, Steven M., Danish Social Movements in a Time of Global Destabilization. Essays on the Heritage of Reventlow and Grundtvig, the Efterskole, the Postmodern. 1996. 421 s. (Spec. s. 104-32, »N. F. S. Grundtvig and the concept of 'the folkelig' «.) 
Boyer, Régis, Histoire des littératures scandinaves. Paris, 1996. S. 10912.

Brandby-Cöster, Margareta, Vägen mellan himmel och jord. Underströmmar av luthersk livsförståelse i Selma Lagerlöfs författarskap. Karlstad, 2000. S. 21-23 (»Luther och Grundtvig«). (Licentiatopgave i religionsvidenskab, Karlstad universitet.)

Bredsdorff, Morten, "Grundtvig og Holberg«. I: Den levende Holberg. Modersmål-Selskabets Arbog. 1984. S. 105-08.

Bruhn, Bodil \& Verner (udg.), Jeg vil sjunge ... 50 sange fra danske sangbøger. 1989. 155 s. (»Rids af skolesangens historie«, s. 10-24; "Sangbøger«, s. 25-30; desuden kommentarer til sangene, af hvilke 9 skyldes G [s. 46-55, 66-68, 86-87 og 102-05].)

Chase, Martin, »The Ragnarok Within. Grundtvig, Jung, and the Subjective Interpretation of Myth «. I: Geraldine Barnes \& Margaret Clunies Ross (red.), Old Norse Myths, Literature and Society. Proceedings of the 11 th International Saga Conference 2-7 July 2000, University of Sydney. Sydney, 2000. S. 65-73.

Christensen, Johs. H. »Ave Maria Magdalene - en kladde«. I: Johs. H. Christensen \& Jens Christiansen (red.), En rig mand. Til Ebbe Kløvedal Reich på 60-årsdagen. 2000. S. 44-63. (Om G's to MM-salmer s. 5560.)

Elbek, Jørgen, »Guds datter«. I hans: Arhundredets bro. Kritiske skitser. 1998. S. 7-12.

Garff, Joakim, SAK. Søren Aabye Kierkegaard. En biografi. 2000. S. 282-88, 661-63. Cf. reg. s. 707.

Gjesing, Knud Bjarne, »N. F. S. Grundtvig«. I: Benedicte Kieler \& Klaus P. Mortensen (red.), Litteraturens stemmer. Gads danske forfatterleksikon. 1999. S. 165-71. Cf. s. 620-22. (2. opl., 2000, med små æmdringer.) 
Grane, Leif, »Grundtvigs kirkelige anskuelse«. I hans: Kristendommen i historien. Udvalgte artikler 1950-1996. 1997. S. 141-47. (Kirkehistoriske Studier, III:5.) (Efterklange - et Grundtvig-seminar, 1983, s. 13744.)

Hansen, Martin A., "O Kristelighed«. I hans: Dagbøger, I-III [i fortløbende paginering]. Udg. af Anders Thyrring Andersen og Jørgen Jørgensen under medvirken af Jørgen Hunosøe og Esther Kielberg. 1999. II s. 954-57, 1235. (Dagbogens seneste optegnelse, 17.6.1955.)

Hauge, Hans, »Postkolonialisme«. I: Johannes Fibiger, Gerd Lütken \& Niels Mølgaard (red.), Litteraturens tilgange - metodiske angrebsvinkler. 2001. S. 369-405. (Heri s. 397-403 læsning af »Danmarks Trøst «, aftrykt s. 473-75.)

Haystrup, Helge, »Fra Grundtvig via Irenæus til Augustin«. I hans: Augustin-Studier, X. 1998. S. 23-90.

Henningsen, Hans, »Er troen virkelig en (høj)skolesag«. I: Niels H. Brønnum, m.fl. (red.), Kamp må der til. Engagementets brydning mellem åbenhed og tradition. Festskrift tilegnet Ole Jensen. 1997. S. 91100.

Henriksen, Aage, »Kærlighedens forvandlingsformer «. I hans: Littercert testamente. Seks kapitler om karlighed. 1998. S. 7-35, spec. s. 13-19. (Om dialogen mellem Jens Baggesen og G, 1815-18.)

Horstbøll, Henrik, Menigmands medie. Det folkelige bogtryk i Danmark 1500-1840. En kulturhistorisk undersøgelse. 1999. S. 179-86 (»Efterklange af det oprindelige: Grundtvigs folkebogsprojekt «). (Danish Humanist Texts and Studies, 19.) (Disputats forsvaret på Aarhus Universitet 11.6.1999.)

Jensen, Jørgen I., "Historiens Palæstina«. I: Ingmar Brohed (udg.), Kyrka och nationalism $i$ Norden. Nationalism och skandinavism $i$ de nordiska folkkyrkorna under 1800-talet. Lund, 1998. S. 117-25. (Bibliotheca Historico-Ecclesiastica Lundensis, 39.) (Cf. Hans Raun Iversen, »Kirkeordning og menighedsforståelse i Danmark. Udviklingen i 1800- 
tallet som baggrund for folkekirkens status i dag«, smst., s. 101-16, spec. s. 111-12.)

Jørgensen, Bo Hakon, Mastetoppe. 100 danske digte - med korte analyser. 1997. S. 97-101. (Odense University Studies in Scandinavian Languages and Literatures, 36.) (Om »Paaske-Liljen«.)

Jørgensen, Theodor, „Grundtvig und Luther. Welche Bedeutung hatte Luther für Grundtvig?« I: Luther im Widerstreit der Geschichte. Erlangen,1993. S. 97-108. (Veröffentlichungen der Luther-Akademie e. V. Ratzeburg, 20.)

Jørgensen, Theodor, »Har folkekirken en fremtid som ekklesiologisk model? Om det protestantiske kirkebegreb, det pluralistiske samfund og Porvoo-erklæringen«. I: Hans Raun Iversen (red.), Vinduer til Guds Rige. Seksten foreloesninger om kirken. 1995. S. 217-31, spec. s. 223-28.

Jørgensen, Aage, »Bøgens Fædreland «. I hans: Bøgens Fadreland - og andre guldalderstudier. 1999. S. 83-108, spec. s. 93-96. (Cf. ndf. u. »Tidsskriftartikler«.)

Kemp, Peter, »Hautes Écoles Populaires au Danemark. Réseau et partenariat pour une démocratie dans une société technologique«. I: Peter Kemp \& Georges Thill (red.), Technologies: Réseaux et Partenariats/ Technologies: Networks and Partnerships. Actes du Cours de l'InterUniversity Centre de Dubrovnok avril 1988. Namur, 1990. S. 113-27, spec. s. 115-20.

Kondrup, Johnny, „Biografisk metode«. I: Johannes Fibiger, Gerd Lütken \& Niels Mølgaard (red.), Litteraturens tilgange - metodiske angrebsvinkler. 2001. S. 59-80. (Heri s. 73-78 læsning af »Strandbakken ved Egeløkke«, aftrykt s. 431-35.)

Langholz, Carl, »Anetavle for N. F. S. Grundtvig (1783-1872)«. I hans: Anetavler for berømte danskere. 1. samling: Digtere og forfattere. 1989. S. 64-72. 
Lundgreen-Nielsen, Flemming, »København: dødsfjende - hjertenskær«. I: Flemming Lundgreen-Nielsen (red.), København loest og påskrevet. Hovedstaden som littercer kulturby. 1997. S. 17-41, spec. s. 33-37.

Lundgreen-Nielsen, Flemming, "Løven i buret. Grundtvig i 1848 «. I: Claus Bjørn (red.), 1848 - det moerkelige år. 1998. S. 127-52, 200-02.

Lundgreen-Nielsen, Flemming, »Grundtvig und Steffens. Die Wechselwirkung zweier berühmter Vettern «. I: Otto Lorenz \& Bernd Henningsen (red.), Henrik Steffens. Vermittler zwischen Natur und Geist. Berlin, 1999. S. 67-83. (Wahlverwandtschaft. Der Norden und Deutschland, 3.)

Löfström, Inge, 'Det eviga i en bägare vatten'. Studier och reflexioner. Stockholm, 1992. 164 s. (Heri bl.a.: "Grundtvig kom aldrig till Sverige. Mänskligt och gudomligt i harmoni - i Danmark«, s. 67-82; "'Det eviga i en bägare vatten'. Martin A. Hansen och den kristna livstron«, s. 8397.)

Martinsen, Kari, Fenomenologi og omsorg. Tre dialoger med etterord av Katie Eriksson. Oslo, 1996. $150 \mathrm{~s}$. (Dialog 2, »Kropp og ånd i praktisk sykepleie«, s. 38-77, om skabelsesfænomenologien bl.a. hos Grundtvig/ Løgstrup.) (Anm.: Hans Hauge, Cekvina Nyt, 1997, nr. 2, s. 55-57.)

Meincke, Inga, "Vox viva - die Suche nach der einen, eindeutigen Stimme. Überlegungen zu N. F. S. Grundtvigs 'Muttersprachenmystik' «. I: Walter Baumgartner \& Hans Fix (udg.), Arbeiten zur Skandinavistik. XII. Arbeitstagung der deutschsprachigen Skandinavistik 16.-23. September 1995 in Greifswald. Wien, 1996. S. 535-46. (Studia Medievalia Septentrionalia, 2.)

Mørch, Søren (red.), Danmarks historie. X: Historiens historie. 1992. S. 255-59 (»Grundtvig«).

Nielsen, Erik A., »En dråbe stærk. Om Grundtvigs 'Paaske-Lilien«. I hans: Lyrikere. 15 udlcegninger og et digt. 2001. S. 100-15, 279. (Oprindelig offentliggjort i Erik Dal-festskriftet Hvad Fatter gjør ..., 1982, s. 334-50; nyskrevet er s. 105-07 om mulig Shakespeare-forbindelse.) 
Nielsen, Jakob Fløe, „Grundtvigs kirkelige anskuelse som bibelsk teologi«. I: Sigfred Pedersen (red.), Bibelsk teologi. 2000. S. 200-18.

Paul, Fritz, „Grundtvig«. I: Rosemarie Müller (red.), Reallexikon der Germanischen Altertumskunde. XIII. Berlin/New York, 1999. S. 122-26.

Pedersen, Kim Arne, "'Solen skinnede og Moder kaldte'. Grundtvigs forhold til sin moder i liv og forfatterskab«. I: Carsten Bach-Nielsen, m.fl. (red.), Ordet og livet. Festskrift til Christian Thodberg. 1999. S. 156-75.

Rasmussen, Jens, Kampen for indflydelse i statskirken. Nicolai Faber, Fyns biskop 1834-1848. Studier i statskirkens organisation, bispeembede, prcestestand og menighedsliv. 1996. S. 45-60, 216-18 (»En kirkelig polemik - forholdet til N. F. S. Grundtvig«). Cf. reg.

Rasmussen, Jens, J. P. Mynster, Sjallands biskop 1834-1854. Kampen for en rummelig kirke. Forholdet til N. F. S. Grundtvig og Grundloven. 1999. $337 \mathrm{~s}$. (Odense University Studies in History and Social Sciences, 224.) (Se reg. s. 327.) (Anm.: Carsten Bach-Nielsen, Fortid og Nutid, 2000, s. 240-41; Svend Bjerg, Politiken 6.1.2000; Niels Gunder Hansen, Berlingske Tidende 30.12.1999; Christian de Fine Licht, Kristeligt Dagblad 15.3.2000; Frands Ole Overgaard, Højskolebladet, 1999, nr. 39, s. 12-13, Dansk Kirketidende, CLII, 2000, s. 42-43.)

Reich, Ebbe Kløvedal, Kun et gastekammer. Historien om den danske folkekirkes fødsel. 1999. S. 36-44.

Rifbjerg, Klaus, »Deilige Solskins-Klæder. N. F. S. Grundtvig: Salmer og sange«. I: Povl Schmidt, m.fl. (red.), Laesninger i dansk litteratur. II: 1820-1900. 1998. S. 26-34, 332.

Rothstein, Klaus, »Jeg vil lære jer at hade«. I hans: Kvinde på Dronning Louises Bro. Essays. 2000. S. 49-63. (Om Grundtvig/Goldschmidtdiskussionen om national identitet.)

[Röhrig, Paul,] Lebendige Erwachsenenbildung. Reflexionen über die Aktualität von N. F. S. Grundtvig. Bederkesa [1990]. 90 s. (Dialog, 10.) (Heri spec. kapitlerne: »Aufklärung durch das lebendige Wort. In dürrer, 
spracharmer Zeit ist an Grundtvigs Erbe zu erinnern«, s. 7-34; »N. F. S. Grundtvig. Das grosse Genie der Volksbildung «, s. 35-46; »Grundtvigs Bedeutung für die deutsche Erwachsenenbildung «, s. 47-57.)

Schjørring, Jens Holger, «Dogmatikkens indledningsproblemer«. I: Niels Henrik Gregersen (red.), Fragmenter af et spejl. Bidrag til dogmatikken. 2. udg., 1993 og 1997. S. 13-58. (Om G s. 20-21, 42-45.) (1. udg., 1992.) (Cf. reg.)

Schjørring, Jens Holger, „Grundtvig«. I: Walter Kasper (udg.), Lexikon für Theologie und Kirche, IV: Franca bis Hermenegild. Freiburg/Basel/ Rom/Wien, 1995. Sp. 1077-78.

Schjørring, Jens Holger, »Trosbekendelse og kirkesyn hos Grundtvig og Bonhoeffer«. I: Carsten Bach-Nielsen, m.fl. (red.), Ordet og livet. Festskrift til Christian Thodberg. 1999. S. 193-208.

Schjørring, Jens Holger, »Grundtvig«. I: Hans Dieter Betz, m.fl (udg.), Religion in Geschichte und Gegenwart. 4. reviderede udg. III: F-H. Tübingen, 2000. Sp. 1311-12.

Shippey, T. A. \& Andreas Haarder (red.), Beowulf. The Critical Heritage. London/New York, 1998. xviii, 591 s. (The Critical Heritage Series.) (Heri om: Jacob Langebek s. 76-77; Grímur Jónsson Thorkelín s. 91-98, 113-16; Peter Erasmus Müller s. 98-107; N. F. S. Grundtvig s. 24-26, 108-13, 143-52, 158-61, 183-85, 241-45; Nicholaus Outzen/Friedrich Christoph Dahlmann s. 123-31; Gísli Brynjúlfsson s. 291-96; Ludvig Schrøder s. 372-73; Frederik Rönning s. 410-15; Axel Olrik s. 497-502.)

Thing, Morten, »Løver og abekatte. Eller hvad er danskhed?« I: Erik Svendsen \& Henrik Ljungberg (red.), Ud af det moderne. Den kritiske tanke anno 2000. [Festskrift til Jørgen Bonde Jensen.] 2000. S. 43-58. (Om Grundtvig/Goldschmidt-debat i 1849.)

Thodberg, Christian, "At tale en sang. Grundtvigs poetiske raptus på prædikestolen «. I: Poul Lindegård Hjorth, m.fl. (red.), Fra Egtvedpigen til Folketinget. Et festskrift til Hendes Majestcet Dronning Margrethe II ved regeringsjubilcet 1997. 1997. S. 245-71. 
Thomsen, Niels, »I Nazareth i trange kår. Overvejelser over folkelighed, kvalitet og grundtvigianisme«. I: Carsten Bach-Nielsen, m.fl. (red.), Ordet og livet. Festskrift til Christian Thodberg. 1999. S. 245-56.

Thyssen, Peter, " 'At sige verden ret farvel' - ars moriendi-traditionen og Grundtvig«. I: Carsten Bach-Nielsen, m.fl. (red.), Ordet og livet. Festskrift til Christian Thodberg. 1999. S. 176-92.

Weniger, Erich, "Grundtvig und der Begriff der historischen Aufklärung«. I hans: Ausgewählte Schriften zur geisteswissenschaftlichen Pädagogik. Ausgewählt von Bruno Schonig. Weinheim/Basel, 1975. S. 51-94. (Tiltrædelsesforelæsning ved Christian-Albrecht-Universität Kiel 25.11.1929; trykt 1930 og påny 1953.)

Østergård, Uffe, Europa. Identitet og identitetspolitik. 1998. S. 358-63 (»Grundtvig og folkekirken«).

Aarnes, Sigurd Aa., »Grundtvig og Norge«. I hans: A dikte en nasjon. Artikler 1966-96 om norsk litteratur. Bergen, 1997. S. 50-65. (Længere version i Mål og makt, nr. 1-2, 1996, s. 64-76.)

\section{Tidsskriftartikler}

Abrahamowitz, Finn, »Fædrelandets ildsjæl«. Samvirke, 2000, nr. 9, s. 56-59.

Allchin, A. M., "The Holy Spirit in the Teaching of N. F. S. Grundtvig«. Grundtvig Studier, 1998, s. 175-89.

Allchin, A. M., "Grundtvig and Coleridge: Heritage and Prophecy«. Grundtvig Studier, 1999, s. 162-72.

Andersen, Kirsten M., "Når salmen bryder ud i sang «. Fønix, XXIII, 1999, s. 214-33, spec. s. 221-30.

Arendt, Rudolph, »Sandt og løgn«. Dansk Kirketidende, CLII, 2000, s. $140-41$. 
Auken, Sune, »Men valgte Livets Storme - bemærkninger om Grundtvig som folkeeje og specialviden«. Højskolebladet, 1998, nr. 14-15, s. 1113.

Auken, Sune, »Oh, synger for dem som Lærker slaa. Om Grundtvig og julen«. Højskolebladet, 1998, nr. 40, s. 10-12.

Auken, Sune, "Stjernernes Morgensang. Om N. F. S. Grundtvigs historiske salme 'Hyrderne ved Bethlehem' «. Grundtvig Studier, 1997, s. 212-27.

Auken, Sune, »Sangværket som udviklingsroman. Om Randi Habersaat Rodes bog 'Barneglad og engleklog' (1996)«. Grundtvig Studier, 1999, s. 195-207.

Auken, Sune, "'At Himlen i Vove dog haver et Speil'. Udkast til en figural læsning af Grundtvigs 'Nyaars-Morgen' «. Transfiguration, I:1, 2000, s. 43-57.

Balle, Thorstein, »At genfortælle det grundtvigske«. Vartovbogen, 1999, s. 104-18.

Balling, Jakob, »Tradition og modernitet i 'Nyaars-Morgen' «. Dansk teologisk Tidsskrift, LXI, 1998, s. 120-32. (Erstatter fejlbefængt version smst. s. 33-45.)

Balling, Jakob, »Creative Recycling. A Note on Two Grundtvigian Hymns«. Grundtvig Studier, 2000, s. 27-35.

Balslev-Clausen, Peter, „Grundtvig og Evangelisk-kristelig Psalmebog (1798)«. Hymnologiske Meddelelser, XXVII, 1998, s. 209-48. (Indgår i temanummer om »Evangelisk-kristelig Psalmebog 1798«.)

Bhattacharya, Asoke \& Tandra Mitra, "People's Education in India. Perspective of Jadavpur University«. Grundtvig Studier, 1998, s. 20210.

Birkelund, Regnar, »Livsoplysning og socialpædagogik. Med det sociale individ som perspektiv, drejer Grundtvigs pædagogiske tanker sig i 
virkeligheden om socialpædagogik!« Tidsskrift for Socialpædagogik, 1999, nr. 3, s. 50-56.

Birkelund, Regnar, „Grundtvigs syn på videnskab og uddannelsen af praktiske embedsmænd«. Nordisk Pedagogik, XX, 2000, s. 117-23.

Björkstrand, Gustav, »Grundtvig, Baltikum och Norden«. Finsk Tidskrift, CXXII, 1997, s. 459-70.

Björkstrand, Gustav, „Grundtvig i finländskt perspektiv«. Grundtvig Studier, 1999, s. 121-37.

Bradley, S. A. J., "The Recovery of England's 'skrinlagt fortid' - a Progressive Report«. Grundtvig Studier, 1999, s. 138-61.

Bradley, S. A. J., »Det er hvad jeg kalder at oversætte digte. Grundtvig as Translator«. Grundtvig Studier, 2000, s. 36-59.

Bradley, S. A. J., »Hvilken Oversættelse! Hvilken Galskab! Translating the Poetry of Grundtvig«. Grundtvig Studier, 2000, s. 60-74.

Brun, Jens, »Baggesen, Grundtvig og selverkendelsen«. Fønix, XXI:4, 1997, s. 16-25.

Brun, Jens, 》Grundtvigs opskrift på en dansk strikketrøje. Havfruen og Bølgernes Søn i ‘Nyaars-Morgen’«. Dansk Kirketidende, CLI, 1999, s. 37-39.

Brun, Jens, »Murens fald. Om Grundtvigs poetiske teologi«. Dansk Kirketidende, CLI, 1999, s. 152-56. (Om »Nyaars-Morgen«)

Bugge, K. E., »Lokal forankring og universelt perspektiv i Grundtvigs salmedigtning«. Prismet (Oslo), XLVI, 1995, s. 214-20.

Bugge, K. E., „Grundtvig-konference i Indien«. Grundtvig Studier, 2000, s. $184-89$. 
Bøye, Merete, "Hallen og havet som eskatologiske modsætninger - i den angelsaksiske poesi og hos Grundtvig«. Grundtvig Studier, 1998, s. $120-41$.

Carlsen, Jørgen, »Livets lyst - om kulturradikalisme og grundtvigianisme«. Højskolebladet, 1998, nr. 40, s. 7-10.

Carøe, Niels Bo, »Grundtvig«. Tidehverv, LXXIII, 1999, s. 97-105.

Christensen, Bent, Niels C. Roland \& Thomas Roland, "Grundtvig og Lolland-Falster og Oxford! Grundtvig'ske forbindelses-tråde mellem Udby, Radsted, Døllefjelde og Oxford i fortid og nutid«. Stiftsbog og landemode-akt for Lolland-Falsters Stift, 1996, s. 25-35. (Cf. Søren Jensen, »Den lærde Frederik Helweg i Købelev«, smst. s. 49-59.)

Christensen, Johs. H., »Friheden og dens grænse - Luther og Grundtvig«. Helsingør Stiftsbog, 1996, s. 25-32.

Dam, Poul, »Noget om Myterne omkring den Clausen'ske injuriesag og Grundtvigs censurperiodes afslutning «. Grundtvig Studier, 1999, s. 7-26.

Ehnevid, Tord, "'Vad sanning är, făr tiden visa'. Grundtvigs sanningsetik«. Grundtvig Studier, 1998, s. 211-64.

Eichberg, Henning, »Modernitetens modsigelser. Konfigurationskonflikter og samfundstænkning i Grundtvigs 'Om Mennesket i Verden' ". Grundtvig Studier, 1998, s. 142-56.

Ertner, Jørgen, »Et ord af Guds Søn. Salmen 'Sov sødt, barnlille' og dens tilblivelse«. Grundtvig Studier, 1997, s. 185-211.

Fisker, Per, ॥'Rim-Brev til Nordiske Paarørende' «. Dansk Kirketidende, CLII, 2000, s. 368-72.

Golf, Olav, »Grundtvig - Hauge og hans venner fram til 1840. Motstandere eller kanpfeller«. Tidsskrift for Teologi og Kirke, LXVII, 1996, s. 97-110. (Prøveforelæsning for den filosofiske doktorgrad, Oslo 26.1.1995.) 
Grane, Leif, "The Incipient Breakdown of the Humanist-Christian Cultural Synthesis in Denmark«. Thorvaldsens Museum. Bulletin 1997, 1997, s. 106-13.

Grane, Leif, "Grundtvigs forhold til Luther og den lutherske tradition «. Grundtvig Studier, 1998, s. 21-41.

Grane, Leif, „Grundtvigs nadversyn - og Luthers. Nogle bemærkninger til en afhandling«. Dansk teologisk Tidsskrift, LXII, 1999, s. 1-17. (Afhandlingen, af Chr. Thodberg i Grundtvig Studier, 1975, er optrykt i forf.'s Syn og Sang, 1989.)

Gregersen, Niels Henrik, "Mennesket som Mikrokosmos. Grundtvigs store digt om 'Menneske-Livet' «. Grundtvig Studier, 2000, s. 75-103.

Gaarsted, Max, "Lyset i danske salmer og sange. Lyset hos Ingemann og Grundtvig«. Dansk Sang, LII:6, 2001, s. 12-18.

Hansen, Gregory, »N. F. S. Grundtvig's Idea of Folklore. Resurrecting Folk-Life through the Living Word«. The Folklore Historian, XII, 1995, s. 5-13.

Hansen, Thorvald, »Grundtvigianism and Danes in America«. Grundtvig Studier, 1998, s. 190-201.

Hauge, Hans, »At læse Grundtvig«. Dansk Kirketidende, CL, 1998, s. 229-33.

Hauge, Hans, „Om salmer og modernitet. Fra Grundtvig til Grotrian«. Kritisk forum for praktisk teologi, nr. 82, 2000, s. 14-24, spec. s. 15-17. (Om »Påskeblomst, hvad vil du her?«)

Heggem, Synnøve, »Grundtvigs kvinnesalmer, - kjærlighetens kjønnsbestemte sang. Om relasjonen Gud - menneske. Presentasjon av et prosjekt«. Dansk Kirketidende, CLII, 2000, s. 36-39 og 56-61.

Henningsen, Hans, »Anmerkungen zur Grundtvigschen Idee aus dänischer Sicht«. Hessische Blätter für Volksbildung, XL, 1990, s. 206-10. 
Holm, Jette, "Grundtvigs prædiken 2. s.e.Trin. 1840«. Grundtvig Studier, 1997, s. 139-47. (Erstatter defekt tekst i 1996-årg.)

Holm, Jette, $»$ Salmen 'At sige Verden ret Farvel', belyst ved Grundtvigs samtidige prædikener«. Grundtvig Studier, 1997, s. 148-84.

Holm, Jette, »Opblomstrer nu, Guds Kirkevange«. Vartovbogen, 1999, s. 71-80. (Om udkast til »I al sin glans nu stråler Solen«.)

Jacobsen, Anders-Christian, "Afgrænsningen mellem sand og falsk skrifttolkning hos Irenæus og Grundtvig«. Grundtvig Studier, 1997, s. 29-52.

Jacobsen, Anders-Christian, »Irenæus. 3die Bogs 40de Kapitel«. Grundtvig Studier, 1998, s. 9-20. (Udgivelse af og kommentar til G's oversættelse.)

Jessen, Peter Neergaard, „Grundtvigs prædikener i 1864«. Grundtvig Studier, 1997, s. 102-38.

Jørgensen, Theodor, »Grundtvig og den lutherske tradition«. Grundtvig Studier, 1998, s. 42-60.

Jørgensen, Aage, »Bøgens Fædreland «. Anderseniana 1998, 1999, s. 21 40, om G s. 27-29. (Også i: Skandinavisztikai Füzetek / Papers in Scandinavian Studies [Budapest], nr. 8, 1998, s. 7-24, om G s. 14-16.) (Uden noteapparat i: Malan Marnersdóttir \& Jens Cramer (red.), Nordisk litteratur og mentalitet. Foredrag fra den 22. studiekongres $i$ International Association for Scandinavian Studies (IASS) arrangeret af Føroyamálsdeild, Fróðskaparsetur Føroya, Førøernes Universitet, 3.-9. august 1998. Føroya Fróđskaparfelag, Tórshavn 2000. Pp. 269-78. (Annales Societatis Scientiarum Færoensis, Supplementum, XXV.) - Samt i: Dansk Kirketidende, CLI, 1998, s. 23-27 og 39-42.)

Kelstrup, Erik, »Grundtvigs anvendelse af modsigelsens grundsætning i 'Kirkens Gienmæle' - filosofisk belyst«. Grundtvig Studier, 2000, s. 126-53. 
Kemp, Peter, "La critique de l'écriture chez N. F. S. Grundtvig. Une éthique de la communication«. Archivio di filosofia, LX:1-3, 1992, s. 485-93.

Kiel, Ulla (medd.), »Grundtvigs optegnelser med titlen: 'Irenæus'«. Grundtvig Studier, 1997, s. 16-28.

Korsgaard, Ove, »Skulle Grundtvig sagt nej till EU?« Ordfront magasin, 1995, nr. 1, s. 40-43.

Korsgaard, Ove, »Grundtvigs oplysningstanker - om at knytte bånd og løse knuder«. Grundtvig Studier, 2000, s. 154-71.

Kredsen, LXIII:1, 1997: bidrag til Studenterkredsens sommermøde 1997, »Rod i det grundtvigske«. (Henrik Wigh-Poulsen, »Barnelivet i den grønne Lund - om en grundtvigsk vision og dens efterliv. Eller: Om at komme hjem til far«, s. 6-27 [G s. 9-15, Jakob Knudsen s. 15-24]; Hans Hauge, »Den danske religion: fra før Anders Nørgaard til Ole Jensen and beyond «, s. 28-48; Martin Zerlang, »Flammeblikke«, s. 4961 [om syn, blik etc. hos G, bl.a. i digtet »Duggen«]; H. C. Wind, "Grundtvig som kommunitarist?«, s. 62-81; Knud Riis, »Det grundtvigske menneskesyn og dets rod«, s. 82-132.)

Kuhn, Hans, "Grundtvig and the War that Changed Danish Identity«. Grundtvig Studier, 2000, s. 190-202.

Kulich, Jindra, $\gg N$. F. S. Grundtvig's Folk High School Idea and the Challenge of Our Times". Lifelong Learning, VII:4, 1984, s. 10-13.

Lathrop, Gordon W., "The Bath and the Table, the Prayer and the Word'. N. F. S. Grundtvig and the Lutheran Contribution to Ecumenical Liturgical Renewal«. Grundtvig Studier, 2000, s. 104-17.

Lodberg, Peter, »Grundtvig i økumenisk perspektiv«. Grundtvig Studier, 1998, s. 157-75.

Lundgreen-Nielsen, Flemming, »Grundtvig as a Danish Contribution to World Culture«. Grundtvig Studier, 1997, s. 72-101. 
Lundgreen-Nielsen, Flemming, »Grundtvig and Copenhagen during Denmark's Golden Age«. Thorvaldsens Museum. Bulletin 1997, 1997, s. 73-95.

Lundgreen-Nielsen, Flemming, "Grundtvig, angelsakserne og Sidste Digt«. Grundtvig Studier, 1999, s. 208-25.

Lyby, Thorkild C., »Grundtvig og Rødding Højskole«. Grundtvig Studier, 1999, s. 65-93.

Lyby, Thorkild C., „ Grundtvigs kirkelige anskuelse og dens konsekvenser«. Vartovbogen, 2000, s. 130-46.

Lyster, Jens, »Et overset katekismusvers af Grundtvig - men hvor meget Grundtvig?« Hymnologiske Meddelelser, XXVI, 1997, s. 30-32.

Michelsen, William, »Om Grundtvig-Selskabet 1947-1997, et tilbageblik«. Grundtvig Studier, 1997, s. 53-71.

Michelsen, William, »Om tankebilledet i Grundtvigs sidste digt. II«. Grundtvig Studier, 1999, s. 226-27. (Tilføjelse til artikel smst., 1995, s. 102-06.)

Mikkelsen, Arild, „Grundtvigske peilinger i et uoversiktlig samfunn om Grundtvig i Norge«. Højskolebladet, 1998, nr. 38, s. 4-6.

Mortensen, Karen Marie, ॥ 'De ikke-egnede' «. Kritisk forum for praktisk teologi, nr. 82, 2000, s. 33-45, spec. s. 38-40 og 41-42. (Om salmer, som ikke medtages i »Forslag til Ny Salmebog«, bl.a. »Med sin alabasterkrukke«.)

Nielsen, Jacob Fløe, "'I al sin glans nu stråler solen'«. Dansk Kirketidende, CLII, 2000, s. 187.

Nielsen, Jens Peter Lund, „Det seksuelles komik i moderne litteratur«. Passage, nr. 34, 2000, s. 9-17. (Heri kort om H. C. Andersen, Grundtvig og Kierkegaard.) 
Ord och Bild, 1998, nr. 4-5: »N. F. S. Grundtvig«, s. 71-115. (Ejvind Larsen, "Samtida och förebådande. Grundtvigs post-moderna position «, s. 73-76; Hans Hauge, »Att läsa Grundtvig. Om buktalare, transplantationsförsök och danska mytologier«, s. 77-88; Kim Arne Pedersen, »Frihet för Loke såväl som för Tor. Grundtvigs syn på kristendom och folkliv«, s. 89-97; Ola Fransson, "Danska bönder och den svenska staten«, s. 98-106; Ove Korsgaard, »Att slå sig samman. Grundtvigs tankar om ett universitet i Göteborg «, s. 107-10; Bernt Gustavsson, »Att sjunka ned i traditionens träsk. Grundtvig och den moderna folkbildningen«, s. 111-15.)

Paludan, Signe, »Tolkning af Grundtvigs salme 'Tag det sorte kors fra graven'«. Hymnologiske Meddelelser, XXVIII, 1999, s. 49-62.

Paludan, Signe, »Grundtvigs salmedigtning set i lyset af Luthers salmedigtning «. Vartovbogen, 2000, s. 147-54.

Paludan, Signe, »En salmes historie«. Dansk Kirketidende, CLII, 2000, s. 172-75. (Om »Nu bede vi den Helligånd» og dens traditionsbaggrund.)

Pedersen, Finn Stendal, »N. F. S. Grundtvig og socialpolitikken i Den grundlovgivende Rigsforsamling i foråret 1849«. Historie, 1999, s. 3258 .

Pedersen, Finn Stendal, $\gg$ The Politician Grundtvig (1783-1872). A Liberal in the Danish Constituent Assembly of 1849«. Scandinavian Canadian Studies, XI, 1998, s. 55-74.

Pedersen, Kim Arne, »Det grundtvigske i dag. Grundtvigianisme og kulturradikalisme - en alt for tæt omfavnelse? « Højskolebladet, 1999, nr. 2, s. 3-6. (Revideret version af bidrag til $O$, dejlige land, cf. ovf.)

Pontoppidan-Thyssen, Anders, $»$ Nationalitet og kirke i Danmark og Slesvig-Holsten 1770-1920 med særligt henblik på Grundtvigs betydning«. Grundtvig Studier, 1999, s. 27-64. (English Summary s. 246-56.)

Rasmussen, Jens. ॥N. F. S. Grundtvig og 'Rationalisterne' i årene 182532«. Grundtvig Studier, 1998, s. 95-119. 
Rasmussen, Jens, $»$ Ritualstriden i 1830 'erne - holdninger hos T. Faber, J. P. Mynster og N. F. S. Grundtvig«. Vartovbogen, 2000, s. 108-29.

Riis, Ole, "An Introduction to Grundtvig«. Church and Life (Askov, Minn.), XLVI:4, 1997, s. 3-5.

Sandvej, Jeppe Berg, »Grundtvigs folkelighedsbegreb«. Faklen, nr. 14, 2000 , s. 32-43.

Schjørring, Jens Holger, »Der nationale Grundtvig und seine Wirkungsgeschichte. Anmerkungen zur Geschichte des Nachbarverhältnisses zwischen Deutschland und Dänemark«. Grundtvig Studier, 1999, s. 17394.

Thisted, Susanne Juhl, »Himmelrøsten på jorderig. Om kirkeklokkens metaforiske betydning i Grundtvigs salmer«. Hymnologiske Meddelelser, XXVIII, 1999, s. 109-15.

Thodberg, Christian, "Grundtvig og den danske gudstjenestetradition i internationalt perspektiv«. Dansk Kirkesangs ärsskrift, 1997, s. 91-112; Vartovbogen, 1999, s. 82-102.

Thodberg, Christian, »Om 'Vor Herre! til Dig maa jeg tye'«. Dansk Kirkesangs årsskrift, 1997, s. 128-44.

Thodberg, Christian, "Grundtvig og Gammel Testamente - den danske Bibel eller Septuaginta«. Grundtvig Studier, 1998, s. 61-80.

Thodberg, Christian, »Den liturgiske eksegese og Grundtvig«. Grundtvig Studier, 2000, s. 118-25.

Thorup, Erik, "'Skolen er en trossag!'« Kvan, nr. 49: Det religiøse, 1997, s. 113-23, spec. s. 118-20.

Vind, Ole, »Grundtvigs bibelske nationalisme«. Humaniora, XI:4, 1997, s. 21-24. 
Vind, Ole, »Grundtvig og nationalismen «/ / Grundtvig og demokratiet «. Højskolebladet, 1998, nr. 10, s. 3-6; nr. 11, s. 6, 8-11. (»I anledning af 150 -året for en dansk revolution «.)

Vind, Ole, »Grundtvig og kvindesagen«. Højskolebladet, 1999, nr. 8, s. 7-11.

Vogel, Norbert, „Grundtvigs Einfluß auf die deutsche Volkshochschule«. Das Forum (München), 1991, Heft 4, s. 14-19.

Wigh-Poulsen, Henrik, »Grundtvig, Esajas og det danske landskab«. Dansk Kirketidende, CLII, 2000, s. 73-77 og 104-10.

Wingren, Gustaf, »Grundtvig och hans budskap till oss idag«. Tro \& Liv, 1995, nr. 3, s. 12-17.

\section{Avisartikler}

Auken, Sune, »Der er fundet forskere derinde«. Information 15.7.1997. (Om »Nyaars-Morgen «.)

Bunkenborg, Jan, »Luft ud efter Grundtvig«. Politiken 6.3.1999. (G som national-religiøs folkeforfører.)

Christensen, Niels Ishøj, »Kong Kristus«. Information 31.3.1999. (Om reminiscenser af kongekristendom hos G.)

Holm, Jakob, »Grundtvig bliver global«. Kristeligt Dagblad 24.8.2000. (Interview med Ebbe Kløvedal Reich i forbindelse med åbning af Gkonference i York.)

Korsgaard, Ove, »Den poetiske videnskab«. Information 27.2.1998. (Om G's oplysningstænkning.)

Kuhn, Hans, »Gegen schönen Schein und 'schwarze Schule'. Grundtvigs Kulturrevolution«. Neue Züricher Zeitung (Literaturbeilage) 5.-6.9.1992, s. 70. (Også i: Literature as Resistance and Counter-Culture, 1993.) 
Lindhardt, P. G., »Grundtvigs bibelsyn«. Kristeligt Dagblad 21.12.1999. (smst. 26.8.1983.)

Mikkelsen, Kirsten Pruzan, "Grundtvig under palmerne«. Berlingske Tidende 9.9.2000. (Om Mitraniketan People's College, Indien.)

Myrdal, Jan, "Grundtvig och den folkligare radikalismen«. Svenska Dagbladet 8.9.1983.

Thomsen, Niels, »Grundtvig og kunsten«. Kristeligt Dagblad 20.1.2001.

Tjørnehøj, Henning, „Grundtvig og folkeligheden«. JyllandsPosten 1.10.2000.

Vind, Ole, »Goethe og Grundtvig«. Politiken 28.8.1999.

\section{Varia}

Andersen, Flemming G., "'Laing sagde mig mundtlig'. Om [Svend] Grundtvigs studierejse til England og Skotland, 1843«. I: Else Marie Kofod \& Eske K. Mathiesen (red.), Traditioner er mange ting. Festskrift til Iørn Piø på halvfjerdsårsdagen den 24. august 1997. 1997. S. 13-17. (Foreningen Danmarks Folkeminders skrifter, 88.)

Aspel, Gudrun, »Erica Simon's nordisk-europæiske arbejde - set i dag «. Vartovbogen, 2000, s. 78-84.

Balle, Thorstein, "At genfortælle 'det grundtvigske'«. Vartovbogen, 1999, s. 104-17.

Borish, Steven, " The Concepts of 'Folkelighed' and 'the folkelig' ". Folkevirke, L:3, 1996, s. 12-15.

Bundegaard, Anita Bay, »Det grundtvigske er et ideal - en samtale med Erling Christiansen [forstander, Grundtvigs Højskole Frederiksborg]«. Højskolebladet, 1998, nr. 36, s. 3-7. 
Carlsen, Jørgen, »Livets lyst - om kulturradikalisme og grundtvigianisme«. Højskolebladet, 1998, nr. 40, s. 7-10.

Engberg, Poul, Den danske sag, 1977. (Anm.: Erik Dahlerup, Dansk Kirketidende, CXXX, 1978, s. 58-59.)

Grell, Helge, Grundtvig og oxforderne, 1995. (Anm.: Walter Rothholz, Iros, 1996, s. 146.)

Groh, Martin, »Zwischen Tradition und Moderne. Persönliche Erfahrungen und Erkenntnisse nach sieben Jahren in der dänischen Erwachsenenbildung«. Grundtvig Studier, 2000, s. 172-83.

Grundtvig Studier, 1995. (Anm.: Søren Peter Hansen, Dansk Kirketidende, CXXXXVIII, 1996, s. 182-85; Ove Paulsen, Prcesteforeningens Blad, LXXXVIII, 1998, s. 15-18.)

Grundtvig Studier, 1996. (Anm.: Poul Engberg, Kristeligt Dagblad 2.1.1997; Kathrine Lilleør Petri, Berlingske Tidende 11.2.1997.)

Grundtvig Studier, 1997. (Anm.: Poul Engberg, Kristeligt Dagblad 15.10.1997.; Ove Paulsen, Proesteforeningens Blad, 88, 1998, s. 15-19.))

Grundtvig Studier, 1998. (Anm.: Rudolph Arendt, Kristeligt Dagblad 31.10.1998; Povl Götke, Weekendavisen/Bøger 6.11.1998; Ole Olesen, Prasteforeningens Blad, LXXXIX, 1999, s. 731-35; Søren Peter Hansen, Dansk Kirketidende, 148, 1996, s. 182-85.)

Grundtvig Studier, 1999. (Anm.: Christian de Fine Licht, Kristeligt Dagblad 29.4.2000; Ole Olesen, Proesteforeningens Blad, LXXXX, 2000, s. 278-81, cf. replik af Bent Christensen s. 393-94.)

Grundtvig og grundtvigianismen i nyt lys, 1983: 2. opl., 1998.

Den Grundtvigske Salmebogsgruppe, »Til Salmebogskommissionen«. Dansk Kirketidende, CLII, 2000, s. 360-67. (Incl. Torben Damsholt, "Grundtvig-salmerne«, s. 365.) 
Jensen, Jørgen I., »Poul Borum 1934-1996«. Grundtvig Studier, 1997, s. 11-15. (Nekrolog.)

Korsgaard, Ove, Kampen om lyset. 1997. (Anm.: Claudia Beindorf, Tijdschrift voor Skandinavistiek, XX:2, 1999, s. 203-07; Knud Michelsen, Grundtvig Studier, 1998, s. 273-76.)

Krab-Johansen, Bjørn, »Grundtvig på nettet«. Prcesteforeningens Blad, LXXXXI, 2001, s. 241-43.

Museumsrådet for København og Frederiksberg (red.), Danskere - 17 tanker om danskere og danskheden. 1992.

Nilsson, Gert, »Tord Ehnevid in memoriam«. Grundtvig Studier, 2000, s. $15-18$.

Pedersen, Kim Arne, »Grundtvig-Biblioteket i Vartov - en bogsamling mellem tradition og fornyelse«. Uddannelseshistorie, 1998, s. 80-88.

Schjørring, Jens Holger, "Helge Grell in memoriam«. Grundtvig Studier, 2000, s. 7-13.

Sørensen, Poul, N. F. S. Grundtvig. 1999. 8. s. (Udg. af Udby pastorat.)

Thaning, Kaj, For menneskelivets skyld, 1971. Koreansk overs., ved Michael W. Chung, 1980; 259 s., 6 pl.

Vartovbogen, 1997. (Anm.: William Michelsen, Grundtvig Studier, 1998, s. 265-67.)

Vind, Ole, »Højskoleværdier historisk set«. Højskolebladet, 2000, nr. 39, s. 12-14.

Warren, Clay (red.), Democracy is Born in Conversations. Re-creating N. F. S. Grundtvigfor Lifelong Learners around the World. USA, 1998. x, 221 s. (Interviews med Per Himmelstrup, Johannes Ingberg, Knud Eyvin Bugge, Jakob Erle, Arne Andresén, Torben Damsholt, Jorgen Brems, Monica Munch, Mogens Godballe, Susanne Botfeldt, Lena von 
Hendrichvoh og Ole Borgå; indledning s. 1-8; efterskrift af Chris Spicer, »Learning from the Danes. Charting New Waters«, s. 171-217.)

\section{Websites}

S. A. J. Bradleys G-site (http://www.grundtviginengland.org.uk) indeholder bl.a. G-salmer på engelsk og en bibliografi over engelsksproget G-relateret litteratur.

Merete Bøyes G-site (http://come.to/grundtvig) indeholder bl.a. tidslinie over G's liv med henvisning til vigtige historiske begivenheder i samtiden. Desuden flere G-tekster online og en brevkasse.

Grundtvig på nettet (http://www.nfs-grundtvig.dk) er et samarbejde mellem Grundtvig-Akademiet, N.F.S. Grundtvigs Fond, Nornesalen, Skårup Statsseminarium m.fl. Sitet (under opbygning i form af en Glandsby med talrige indgange) indeholder en fuldtekstdatabase med tekster af Grundtvig online og søgefaciliteter. 